\title{
Notes
}

\section{Double Marking in Arctic Wolves, Canis lupus arctos: Influence of Order on Posture}

\author{
FRED H. HARRINGTON
}

Department of Psychology, Mount Saint Vincent University, Halifax, Nova Scotia B3M 2J6 Canada

Harrington, F. H. 2006. Double marking in Arctic Wolves, Canis lupus arctos: Influence of order on posture. CanadianField Naturalist 120(4): 471-473.

Double marking by Arctic Wolves (Canis lupus arctos) was recorded by Mech (2006) from a pack on Ellesmere Island, Nunavut, Canada, during 16 summers between 1986 and 2005. Using his data on the frequency of occurrence for each of the four postures used by Wolves for urine marking (males - raised leg and stand urinations; females - flexed leg and squat urinations), the probabilities of occurrence for each of eight possible double mark sequences were determined and compared with observed frequencies. Females were somewhat but not significantly more likely to initiate double mark sequences. There was no evidence for any bias in the posture used to initiate a double mark sequence, but assertive postures by both males and females nearly always completed the sequence, occurring much more often than expected by chance.

Key Words: Arctic Wolves, Canis lupus arctos, scent-marking, double marking, pair bonding, mate guarding, urine-marking, Ellesmere Island, Nunavut, Canada.

Double marking, in which a mated pair urine marks a single site in quick succession, is commonly observed in Wolves (Canis lupus) (Harrington and Asa 2003), although evidence from wild Wolves is often inferred from the pattern of urine marks on snow (Peters and Mech 1975; Rothman and Mech 1979). Direct observations, such as those of Mech (2006), permit the identification of the postures used in marking, from which underlying motivation might be inferred. Males may use either raised-leg urinations (RLUs) or standing urinations (STUs) and females either flexed-leg urinations (FLUs) or squat urinations (SQUs), with the former posture for either sex considered to be more reflective of aggressive or assertive motivation (reviewed by Harrington and Asa 2003). Thus there are eight possible forms that a double marking sequence can take. Mech (2006) has presented data on urine-marking in Wolves, recorded by direct observation from Arctic Wolves, Canis lupus actus, during the summer. Among those data are 24 cases of double marking (Table 1), and the reported finding that the more assertive postures (RLUs and FLUs) occur more frequently in double marking. The purpose of this note is to extend the analysis of those data in order to offer more insight into the motivation behind double marking.

\section{Methods}

A dominant adult Wolf may urine-mark using either posture appropriate for its sex. This analysis seeks to determine whether there is a non-random pattern in the use of either posture, by either sex, in double marking compared to urine-marking in general. Therefore I first determined the overall frequency of each urination pos-
TABLE 1. Urination postures used during double marking by Arctic Wolves during summers 1986-2005 on Ellesmere Island, Nunavut, Canada. Male postures: raised-leg [RLU] and standing [STU] urinations; female postures: flexed-leg $[\mathrm{FLU}]$ and squat $[\mathrm{SQU}]$ urinations. (Data from Mech 2006).

\begin{tabular}{lc}
\hline \hline & Male Initiated Double Marks \\
\hline RLU-FLU & 6 \\
RLU-SQU & 1 \\
STU-FLU & 2 \\
STU-SQU & 0 \\
& Female Initiated Double Marks \\
\hline FLU-RLU & 9 \\
FLU-STU & 0 \\
SQU-RLU & 6 \\
SQU-STU & 0 \\
\hline \hline
\end{tabular}

ture that occurred exclusive of double marking (Table 2) to yield two base rates, one for the probability of occurrence for each of the postures overall and another for the probability of the occurrence of each form within a sex. From these probabilities, one can calculate expected frequencies for each form of double mark, under the assumption that the postures used in double marking simply represent random combinations of the postures utilized otherwise. This is done by multiplying the value from row 1 (the random probability the posture will occur overall and thus initiate a sequence) with the value from row 2 (the random probability the other sex will use one of its two alternative postures to complete the double mark). Thus, for example, the 
TABLE 2. Calculation of the probability of occurrence for each of the urination postures used by Arctic Wolves on Ellesmere Island, Nunavut, Canada during summers 1986-2005.

\begin{tabular}{llllll}
\hline \hline & \multicolumn{4}{c}{ Urination posture } & \\
\cline { 2 - 5 } & RLU & STU & FLU & SQU & Total marks \\
\hline Total marks & 121 & 30 & 47 & 70 & 268 \\
Minus double marks & -22 & -2 & -17 & -7 & -48 \\
Non-double mark urinations & 99 & 28 & 30 & 63 & 220 \\
(1) Probability of posture (overall) & 0.45 & 0.13 & 0.14 & 0.28 & 1.00 \\
(2) Probability of posture (within sex) & 0.78 & 0.22 & 0.32 & 0.68 & $1.00 /$ sex \\
\hline \hline
\end{tabular}

TABLE 3. Expected and observed frequencies of occurrence for each of the eight different forms of Wolf double marking, for Arctic Wolves on Ellesmere Island, Nunavut, Canada during summers 1986-2005. Expected frequencies are based on the combined probability of occurrence for each posture in the sequence (from data in Table 2), under the assumption of independence of occurrence for each posture type and based on a sample size of 24 .

\begin{tabular}{lllll}
\hline & \multicolumn{4}{l}{ Double urination mark sequence } \\
\cline { 2 - 5 } Male initiated sequences & RLU-FLU & RLU-SQU & STU-FLU & STU-SQU \\
\hline Expected frequency & 3.5 & 7.3 & 1.0 & 2.1 \\
Observed frequency & 6 & 1 & 2 & 0 \\
Probability of occurrence & 0.144 & 0.306 & 0.042 & 0.088 \\
\hline \hline Female initiated sequences & FLU-RLU & FLU-STU & SQU-RLU & SQU-STU \\
\hline Expected frequency & 2.6 & 0.7 & 5.2 & 1.5 \\
Observed frequency & 9 & 0 & 6 & 0 \\
Probability of occurrence & 0.109 & 0.031 & 0.218 & 0.062 \\
\hline \hline
\end{tabular}

probability for an RLU/SQU double mark to occur at random is $0.45 \cdot 0.68=0.306$, whereas a double mark in the reverse order (SQU/ RLU) is expected less often $(0.28 \bullet 0.78=0.218)$, primarily because males are more likely to use dominant postures overall than are females (Table 3).

\section{Results}

Three questions can be addressed using the probabilities generated in Table 3. First, is one sex more likely to initiate a double marking sequence? Although females initiated $63 \%$ of the double marks observed, compared to the expected frequency of $42 \%$, this increase was not greater than expected by chance $\left(\chi^{2}=2.10, \mathrm{df}=1, \mathrm{~ns}\right)$. Second, is the first mark more likely to be from an assertive posture than otherwise? Again, although twice as many double marks were initiated using the more assertive RLU and FLU postures, this was expected overall, given the high rate of assertive posturing $(59 \%)$ among dominant Wolves $\left(\chi^{2}=0.322, \mathrm{df}=1, \mathrm{~ns}\right)$. Finally, is the second mark which completes the double mark, more likely to be from an assertive posture? Here, the data indicate a highly significant deviation from expectations $\left(\chi^{2}=13.90\right.$, df $=1, P<0.001)$. All but one of the second marks involved either RLU or FLU postures. The one exception was an RLU by the male followed by a SQU by the female. Males increased their use of RLUs from a base rate of $78 \%$ in other situations to $100 \%$ when completing a double mark, while females increased their use of FLU postures even more dramatically, from $32 \%$ overall to $89 \%$ in double marks.

\section{Discussion}

Several captive studies have found that dominant female Wolves are usually the initiators of double marks $(93 \%$ of double marks, $n=23$, Rothman and Mech 1979; 64\%, $n=36$, Mertl-Millhollen et al. 1986). In a sample of over 700 double marks by free-ranging Coyotes (Canis latrans), Gese and Ruff (1997) found that double marking was initiated by females $75 \%$ of the time. Unfortunately, none of the previous studies tested observed initiation rates against expected rates, based on the overall frequency of marking by individuals of each sex, as I have done here. However, the females observed by Mech (2006) did initiate double marking more often than expected, at a rate $(63 \%)$ comparable to previous studies, so the lack of statistical significance for this result may be an artifact of small sample size. Thus it seems likely that double marks are more likely to begin as urinations by dominant females.

Mertl-Millhollen et al. (1986) found that 94\% of double marks in their captive pack were initiated by RLUs (they combined RLUs and FLUs in their analyses). Unfortunately, although they indicate that RLUs comprised the majority of the marks they recorded, they do not present their data in a manner to allow testing of expected versus observed rates for the postures. In the present study, although the initial posture used in a double mark was most often an 
assertive one (RLU or FLU), this is to be expected, given the relatively high rate of these postures in dominant individuals. This analysis suggests that the initial mark of a double mark occurs as an independent event, influenced by a combination of internal factors (arousal, hormones, urine load, etc.) and features of the environment (smells of old marks, food odors, conspicuous visual objects, etc.), but not with the deliberate intent to initiate a double mark sequence. For example, when Wolves are traveling, the lead Wolf is typically the initiator of double marks (Mech 1999); as it encounters sites which elicit its marking, the opportunity for double marking is then created for the trailing Wolf.

The second mark, however, is highly influenced by the presence of the first, and either its freshness, individual identity, chemical composition, or its mere presence at a specific location induces the second individual to use the more assertive RLU or FLU posture. Mertl-Millhollen et al. (1986) likewise found that all but one second mark was either an RLU or FLU; the one exception was a SQU (they combined SQUs and STUs) that followed another SQU. Thus the second mark of a double mark likely represents an increased level of arousal on the part of the marker. Whether that arousal represents generalized excitement, increased sexual motivation or increased aggressive (protective) motivation is not possible to determine here. A variety of hypotheses have been advanced to account for double marking: pair bonding, reproductive synchronization, mate guarding, and territorial defense being among the most common (Rothman and Mech 1979; Mertl-Millhollen et al. 1986; Gese and Ruff 1997). The tight relationship between the frequency of double marking and successful reproduction in Wolves (Rothman and Mech 1979; Asa et al. 1986; Mertl-Millhollen et al. 1986; Peterson et al. 2002) suggests that mating related functions, including mate guarding by the male, are most likely.

\section{Acknowledgments}

This note grew out of a manuscript review. I would like to thank L. D. Mech and F. R. Cook for the invitation to prepare this paper and for their willingness to expedite its consideration. I also thank my students for their patience in receiving their final grades while I worked on the manuscript.

\section{Literature Cited}

Asa, C. S., U. S. Seal, E. D. Plotka, and L. D. Mech. 1986. Effect of anosmia on reproduction in male and female Wolves (Canis lupus). Behavioral and Neural Biology 46: 272-284.

Gese, E. M., and R. L. Ruff. 1997. Scent-marking by Coyotes, Canis latrans: the influence of social and ecological factors. Animal Behaviour 54: 1155-1166.

Harrington, F. H., and C. S. Asa. 2003. Wolf communication. Pages 66-103 in Wolves: Behavior, ecology, and conservation. Edited by L. D. Mech and L. Boitani. University of Chicago Press, Chicago, U.S.A. 428 pages.

Mech, L. D. 1999. Alpha status, dominance, and division of labor in Wolf packs. Canadian Journal of Zoology 77: 11961203.

Mech, L. D. 2006. Urine-marking and ground-scratching by free-ranging Arctic Wolves, Canis lupus arctos, in summer. Canadian Field-Naturalist 120: 475-479.

Mertl-Millhollen, A. S., P. A. Goodmann, and E. Klinghammer. 1986. Wolf scent marking with raised-leg urination. Zoo Biology 5: 7-20.

Peters, R., and L. D. Mech. 1975. Scent-marking in Wolves: A field study. American Scientist 63: 628-637.

Peterson, R. O., A. Jacobs, T. D. Drummer, and L. D. Mech. 2002. Leadership behavior in relation to dominance and reproductive status in gray Wolves. Canadian Journal of Zoology 80: 1405-1412.

Rothman, R. J., and L. D. Mech. 1979. Scent-marking in lone Wolves and newly formed pairs. Animal Behavior 27: 750-760.

Received 24 December 2006

Accepted 24 December 2006 